\title{
New navel orangeworm sanitation standards could reduce almond damage
}

by Bradley S. Higbee and Joel P. Siegel

The navel orangeworm (NOW), a primary pest of almonds and pistachios in California, is controlled in part by sanitation, with a current threshold of two mummy nuts or fewer per tree. However, almond and pistachio acreage has increased dramatically since the tree mummy threshold was established. This study addresses the impact of this expansion and the possible need for a more stringent standard. Beginning in 2002, the Paramount Farming Company conducted a series of large-scale studies reevaluating the current tree mummy threshold in almond orchards, as well as the impact of ground mummies and proximity to pistachio orchards. The data supports a more stringent threshold of 0.2 mummies per tree. In addition, a new threshold for ground mummies of four per tree for 'Nonpareil' almonds is supported in Kern County, although this needs to be validated in other regions. Proximity to pistachios was an important risk factor for navel orangeworm damage of $2 \%$ or less in almonds. Likewise, the influence of pistachios extended 3 miles from the center of the 10-acre almond orchard sections in our experiments to the margin of the nearest pistachio orchard.

lmond and pistachio plantings
comprise more than 880,000 acres
in the Central Valley (NASS 2006). Al-
monds account for about $83 \%$ and pis-
tachios for about $17 \%$ of these plantings
( 730,000 and 153,000 acres, respectively).
'Nonpareil' is the most popular almond
variety, comprising $37.7 \%$ of all stand-
ing acreage in 2006, and 'Kerman' com-

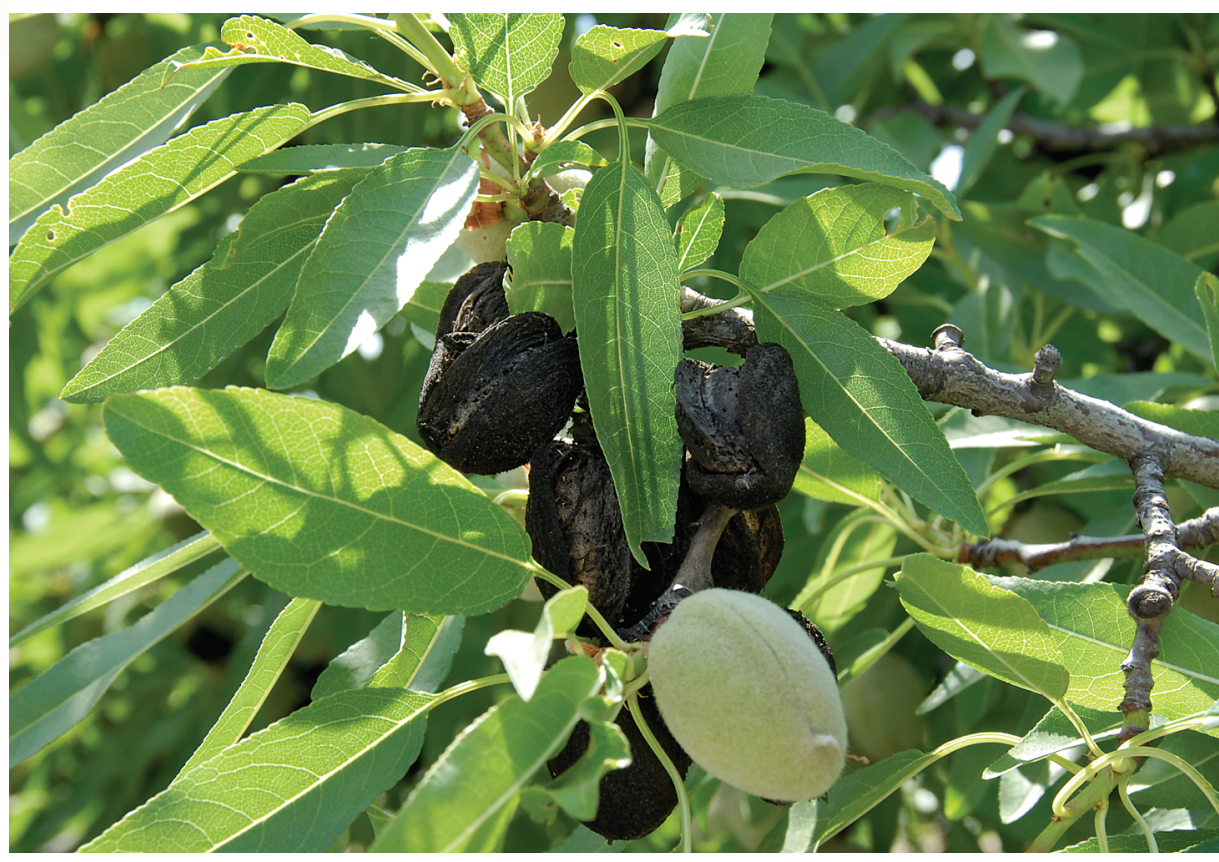

Sanitation practices in almond orchards can have a significant impact on insect pest damage. Almond "mummies" remaining on the tree after harvest provide overwintering sites for navel orangeworm, which then infests the new crop.

prises almost all pistachio plantings in California (see page 18). From 2003 to 2007 , there has been unprecedented expansion in the acreage of both crops: $30 \%$ for almond and $31 \%$ for pistachio.

In 2005, the combined farm-gate value of almonds and pistachios was approximately $\$ 2.9$ billion, according to the Almond Board of California. These crops contribute substantially to the U.S. export balance of trade. Approximately $67 \%$ of the almond (ABC 2006) and $49 \%$ of the pistachio crop was exported in 2005, according to the California Pistachio Industry Annual Report. Kern County had the single greatest concentration of both crops in 2005 , with $20 \%$ of total standing almond acres $(131,400)$ and $31.9 \%$ of total standing pistachio acres $(48,770)$ (NASS 2006).

Navel orangeworm (NOW), Amyelois transitella Walker (Wade 1961), is the major pest of almonds and pistachios in California, and direct damage by this insect can exceed 30\% in both crops. During the late 1970s through the early 1980s, navel orangeworm devastated the almond crop, causing average damage of 8.8\% in 1978 (F.G.
Zalom, personal communication). By the late 1980s, average damage in almonds was reduced to approximately $4 \%$, due to the efforts of researchers at the U.S. Department of Agriculture (USDA) (Curtis 1979) and the University of California (Engle and Barnes 1983; Zalom et al. 1984).

This reduction in navel orangeworm damage was accomplished via a massive commitment to orchard sanitation, using a threshold of no more than two unharvested (mummy) nuts remaining in each tree, along with early harvest of the 'Nonpareil' crop and on-farm fumigation with insecticides after harvest (UC IPM Online 2007). These practices lowered damage by both reducing navel orangeworm populations and removing nuts before they could become infested by the large populations of navel orangeworm that occur from August through September.

While the $4 \%$ damage level was satisfactory for approximately 20 years, both food-quality standards and commodity values are dynamic, and today there is even less tolerance for damage. Since 2002, the almond industry's average 

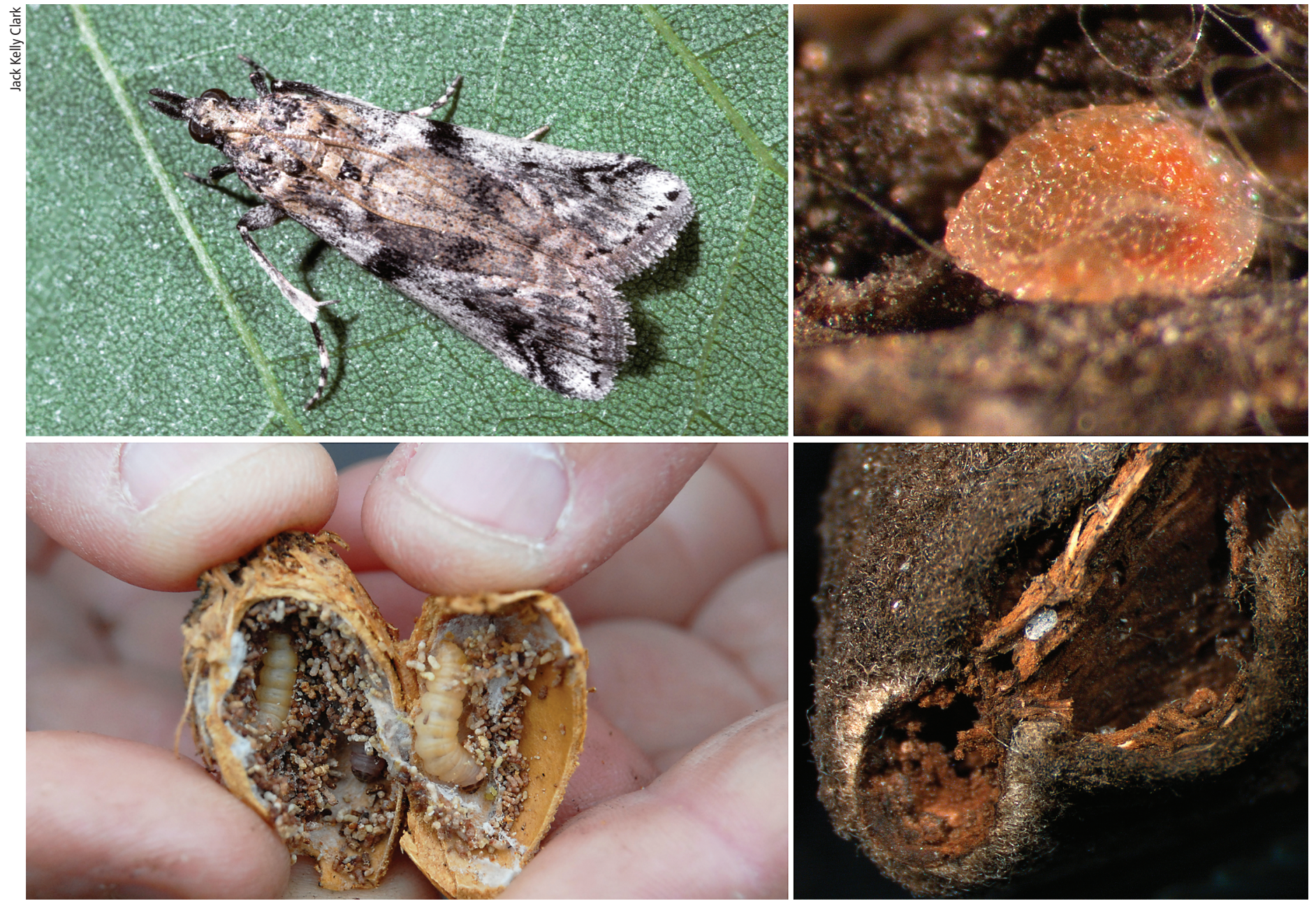

Navel orangeworm control can be achieved in almonds by careful orchard sanitation, early harvest of the 'Nonpareil' variety and postharvest fumigation with insecticides. Clockwise from top left: a navel orangeworm adult; a fertile navel orangeworm egg laid on a mummy almond; a hatched egg; and an almond mummy infested with navel orangeworm larvae.

damage goal for navel orangeworm has been $2 \%$ or less. Factors contributing to this current threshold include the crop's increased value and the association of kernel damage by navel orangeworm with aflatoxin contamination, a major quality concern (Schatzki and Ong 2001; ABC 2006). In addition, the European Union - the largest market for California almonds - has imposed more-stringent import standards that have lowered the allowable level of aflatoxin B1 to 2 parts per billion (OJEU 2007).

In order to reduce navel orangeworm damage and increase almond quality, the Paramount Farming Company initiated research in Kern County in 2002 to evaluate the complex interactions between current sanitation practices, orchard damage history and proximity to an alternate navel orangeworm host (pistachios). Using pooled data from 2003 through 2006, we report on how 'Nonpareil' kernel damage is affected by numbers of both tree and ground mummies, as well as proximity to pistachios.

\section{Post-sanitation studies}

Between December 2002 and February 2006, a series of long-term, labor-intensive studies on mummy abundance following sanitation was conducted in ranches belonging to all divisions of the Paramount Farming Company in Kern County. More than 50 ranches were divided into 160 -acre blocks, which were then subdivided into 40 -acre plots, which in turn were quartered into the 10-acre sections comprising our sample units.

Abundance of mummies. Between January and mid-February, 2003 through 2006, we selected four adjacent trees from each of two consecutive rows (four 'Nonpareil' trees and four pollinizer trees) in each 10 -acre section. (Almonds are not self-compatible and in order to achieve maximum yield, 'Nonpareil' must be pollinated by varieties other than itself. As a consequence, any block of almonds contains at least two different varieties.) Separate counts were made of nuts on the ground and those remaining in the trees. All of the fallen nuts from outside the drip line (or berm) between the eight trees were counted, and nuts in the trees were knocked down with bamboo poles (poling) and then counted. The average number of mummies per tree was calculated for both fallen nuts and nuts remaining in the tree for every year of our study. A total of 1,920 sections was used in this analysis, corresponding to 19,200 acres and 15,360 trees. In 2003 and 2004, all these mummies were collected and dissected, 
and data for the 2 years were pooled (233,821 ground mummies and 7,371 tree mummies).

Damage to kernels. In August and early September, 2003 through 2006, within 5 days of harvest, samples of 1,500 to 2,000 nuts were collected from these same 10 -acre sections by walking a diagonal transect and taking 50 to 100 nuts at intervals of approximately 100 feet. A total of 2,596,008 kernels was obtained by a combination of hand-cracking and a small hulling and shelling machine. All kernels were examined using a lighted $3 \times$ magnifier, by personnel trained to identify common insect and cultural defects. On several occasions, subsamples were sent to a Paramount processing plant for independent grading, and the processor grades were in agreement with the laboratory grades.

Damage to kernels was scored and descriptive statistics including mean, standard deviation and pairwise correlations were calculated using JMP software (v. 7.0.1, SAS Institute, Cary, NC). In addition, relative risk, a statistic commonly used in epidemiology to evaluate the likelihood of a dichotomous outcome (one of two outcomes; in this study the outcome of interest was damage of at least $2 \%$ ) was used to compare damage differences between the tree and ground mummies, and to assess differences in kernel damage by rounding the navel orangeworm damage to the nearest tenth and then contrasting all sections with damage of $2 \%$ or more with sections that had damage below this level (Kelsey et al. 1986). Distance in feet was calculated from the center of each almond section to the margin of the nearest pistachio block using ArcMap (ESRI, Redlands, CA) and the Paramount Farming Company GIS mapping database.

\section{Damage higher in tree mummies}

The average number of tree mummies was 0.7 ( \pm 5.0 standard devia-

\section{In order to properly sanitize an almond orchard in Kern County, it is essential to remove mummies from the trees and destroy them on the ground.}

tion [SD]) and the range was 0 to 69.7 per tree, while the average number of ground mummies was 5.0 ( $\pm 5.3 \mathrm{SD}$ ) and the range was 0 to 43.7 per tree. In the pooled dataset for 2003 and 2004, $13.64 \%$ of tree mummies and $7.91 \%$ of ground mummies collected were infested with navel orangeworm. The relative risk for tree-mummy compared to ground-mummy infestation was 1.72 (Chi square $=277, P<0.0001$ ), indicating that tree mummies were 1.72 times as likely to be infested as ground mummies. This infestation disparity is likely due to differential mortality between navel orangeworm in trees and on the ground, but we did not specifically address this in our study. A similar pattern exists in pistachios collected in February (Siegel et al. 2008), but the study did not specifically determine causes of mortality. The average distance from the center of the almond sections to the margin of the closest pistachio block was 8,600 feet (1.6 miles).

In this study, the average kernel damage per sample due to navel orangeworm was $1.6 \%$ ( $\pm 2.3 \%$ SD) and the range was 0 to $20.8 \%$. The standard deviation was greater than the means for mummies and kernel damage due to the inclusion of sections with no navel orangeworm damage and/or no mummies.

The correlations among these variables using the parametric statistic, Pearson product moment coefficient (r), are summarized in table 1 . Tree mummies were the most strongly correlated with navel orangeworm damage $(0.46$, $P<0.00001)$, followed by ground mum- mies $(0.23, P<0.00001)$. There was a negative correlation between navel orangeworm damage and distance to the pistachio margin $(-0.29, P<0.00001)$, indicating that damage decreased with distance. Tree and ground mummies were moderately correlated $(0.39$, $P<0.00001)$, indicating that when tree mummies were high in a section so were ground mummies, but there was considerable variation. Both tree and ground mummies were negatively correlated with distance to the pistachio margin $(-0.09, P<0.0001 ;-0.06, P<$ 0.005 respectively). These marginal correlations are statistically significant due to the large sample size, and they indicate that there was a slight tendency for fewer mummies to be recovered closer to the pistachio margins.

\section{Mummies and new crop damage}

Tree mummies. Damage in the new crop exceeded the $2 \%$ threshold when there were 0.7 mummies or more per tree in the winter (table 2 ), a reduction of $65 \%$ from the current guideline. However, further relative risk analysis supports a more stringent threshold of 0.2 mummies per tree. When sections containing 0.2 or more mummies per tree were compared to sections that had fewer than 0.2 mummies per tree, the relative risk was 2.15 (Chi square $=156, P<0.0001)$, indicating that they were 2.15 times as likely to have kernel damage equal to or exceeding the $2 \%$ threshold. In addition, other factors beside the number of tree mummies

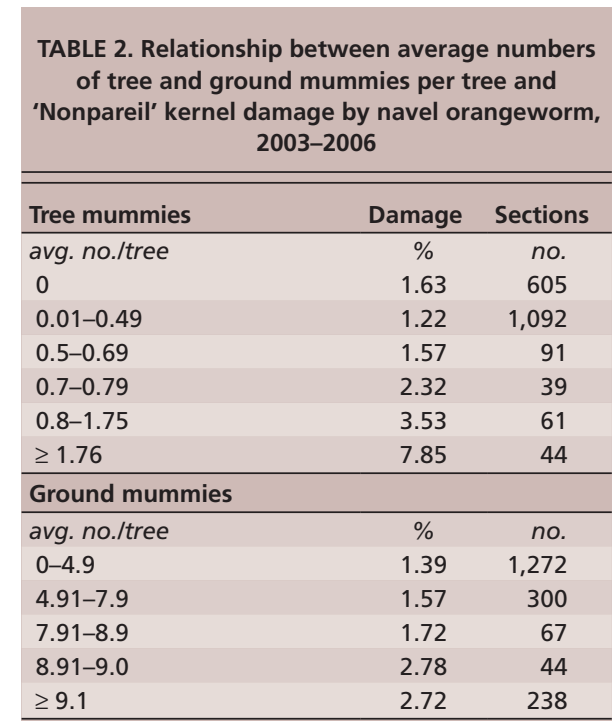

TABLE 1. Correlations among 'Nonpareil' kernel damage by navel orangeworm (NOW), mummies per tree and distance to nearest pistachio margin, 2003-2006

\begin{tabular}{lcccc}
\hline \hline & NOW damage & Tree mummies & Ground mummies & Distance \\
\hline NOW damage & 1.00 & 0.46 & 0.23 & -0.29 \\
Tree mummies & 0.46 & 1.00 & 0.39 & -0.09 \\
Ground mummies & 0.23 & 0.39 & 1.00 & -0.06 \\
Distance & -0.29 & -0.09 & -0.06 & 1.00 \\
\hline
\end{tabular}


clearly influence navel orangeworm damage, because in the sections that lacked tree mummies, the average kernel damage was $1.6 \%$.

Ground mummies. In this study, the number of ground mummies per tree was also related to damage in the new crop (table 2). We found that kernel damage exceeded the current guideline of $2 \%$ when there were 8.9 or more ground mummies per tree. Use of the statistic relative risk indicated that a more stringent threshold of four ground mummies per tree is justified, because sections containing four or more mummies were 1.34 times more likely to have kernel damage exceeding the $2 \%$ threshold than sections with fewer than four mummies on the ground (Chi square $=13.6, P<0.0001$ ) .

There is currently no established threshold for ground mummies. We suggest using an average of four ground mummies per tree for Kern County. We did not establish causality in this study, and mummies on the ground may harbor the overwintering navel orangeworm population, serve as a host for the first generation of the new crop year, or both. What is clear is that mummies on the ground were more than 36 times as prevalent as mummies in trees in the pooled dataset for 2003-2004, and these ground mummies may contribute to navel orangeworm damage due to their abundance. In order to properly sanitize an almond orchard in Kern County, it is essential to remove mummies from the trees and destroy them on the ground.

\section{Proximity to pistachio}

Damage caused by navel orangeworm decreased as distance to the nearest pistachio margin increased (fig. 1). The best fit was obtained using this quadratic equation: \% 'Nonpareil' kernel damage $=0.0265156-0.0000016$ $\times$ distance $+0.00000000013 \times$ (distance $-8,889.8)^{2}$.

Although this equation is statistically significant ( $F$ ratio $112.3, P<$ $\left.0.0001, r^{2}=0.105\right)$ it does not account for most of the variation, confirming that other factors also play a role in navel orangeworm damage. The relationship between damage and pistachio proximity declined with distance and ceased somewhere between 14,000 and 15,000 feet (table 3). Navel orangeworm damage was highest in the almond sections that were 0.25 mile or less from pistachios; there were 87 sections in this class and $55.2 \%$ of them had damage of $2 \%$ or more. At a distance of 3 miles or more from pistachios, there were 1,752 almond sections and $26.7 \%$ of them had damage of $2 \%$ or more. In contrast to sections inside the 3-mile limit, those beyond 3 miles $(15,840$ feet) were $25 \%$ to $50 \%$ less likely to have damage that exceeded the $2 \%$ threshold (data not shown).

\section{Reducing NOW damage to $2 \%$}

Mummy abundance. In order to meet a new threshold of $2 \%$ or less kernel damage in Kern County, the average number of mummies should be reduced to 0.2 per tree, and an additional threshold should be established of four ground mummies per tree after mummy destruction by flail mowing. In a 100-tree planting per acre, these new standards correspond to 20 tree mummies and 400 ground mummies per acre, leaving an acceptable total of 420 or more nuts per acre.

Sanitation. Assuming that an average 'Nonpareil' almond tree in a 1-acre planting bears between 12,000 and 18,000 nuts (UC 2006), and that the accompanying pollinizer varieties bear the same number of nuts, there is a potential load of $1,200,000$ to $1,800,000$ almonds per acre before harvest. Harvest operations and subsequent sanitation must remove or destroy $99.965 \%$ to $99.977 \%$ of these nuts in order to successfully meet the challenge of sanitation to ensure $2 \%$ or less kernel damage. Using these estimates, our current average sanitation efficiency ranged from $99.953 \%$ to $99.969 \%$. Economic analysis is needed to establish a cost-benefit relationship between more stringent sanitation and economic return, in order to enable growers to determine the optimal amount of resources to devote to these practices.

Pistachio proximity. Pistachios as far away as 3 miles from the center of almond blocks may contribute to navel orangeworm damage. Further research

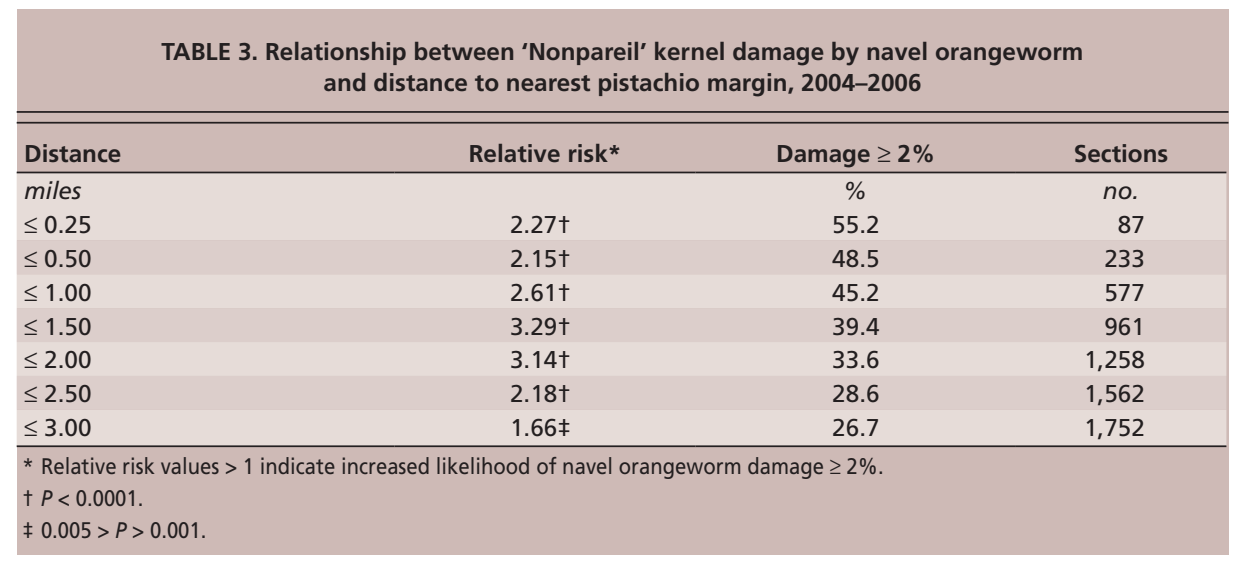




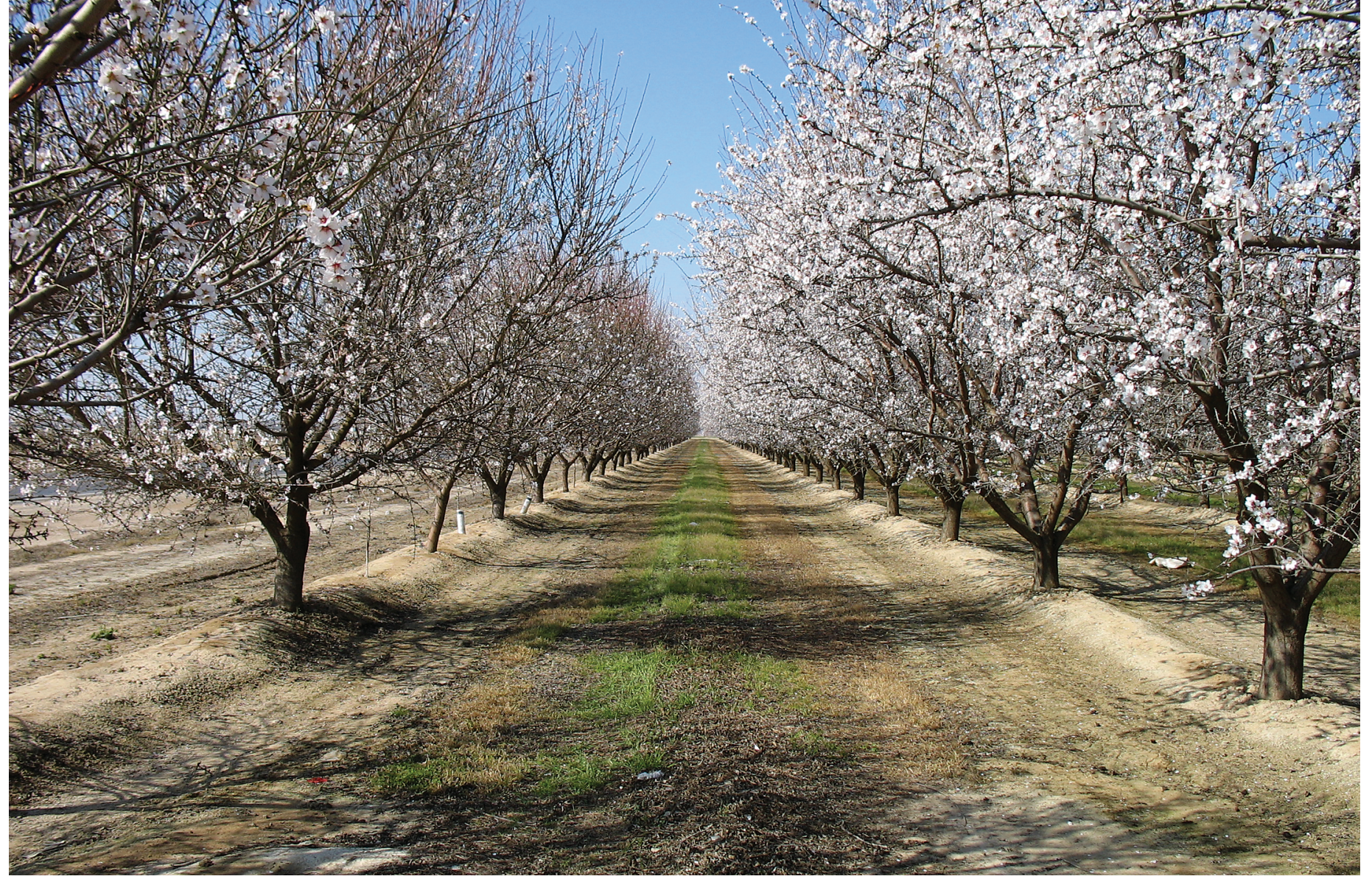

is needed to develop a coordinated strategy for managing this pest in both crops, as well as to determine whether additional measures are necessary to manage almonds in proximity to pistachios. Initial studies on the extent of navel orangeworm movement between almonds and pistachios indicate that in pistachios, male navel orangeworm can move up to 1,100 yards in 1 day while females moved up to 100 yards in 1 day (Burks and Higbee 2006).

Conditions vary throughout the growing regions of the Central Valley and there are likely to be differences that influence the factors identified in the Kern County study. Therefore it is essential to validate these findings in other Central Valley areas. Collaborative studies between USDA, UC, UCCE and Paramount Farming Company researchers are under way as part of a newly established areawide program for the control of navel orangeworm in almonds, pistachios and walnuts.

B.S. Higbee is Research Entomologist, Paramount Farming Company, Bakersfield; and J.P. Siegel is Research Entomologist, USDA Agricultural Research Service, San Joaquin Valley Agricultural Sciences Center, Parlier. The authors thank the staff of the Entomology Laboratory at Paramount Farming Company, particularly Lori Smith and Mike Bryant, for technical assistance and gathering the tremendous amount of data required for this study. We also thank Scott Guseman and Lyndi Smith for their assistance with data management and Gary Schengel for his invaluable help in mapping the orchards. We thank Lawrence Lacey and Joseph Smilanick for their constructive comments on the manuscript.

\section{References}

[ABC] Almond Board of California. 2006. Orchard sanitation and navel orangeworm control. Fact sheet. Modesto, CA. 1 p. http://almondboard.com.

Burks CS, Higbee BS. 2006. NOW mating disruption, dispersal and damage prediction. Proc 34th Annual Almond Industry Conf. Modesto, CA. p 1-19.

Curtis CD. 1979. Implementing orchard cleanup. Almond Facts 44:20-1.

Engle CE, Barnes MM. 1983. Cultural control of navel orangeworm in almond orchards. $\mathrm{Cal} \mathrm{Ag}$ 37(9-10): 19

Kelsey JL, Thompson WD, Evans AS. 1986. Methods in Observational Epidemiology. New York: Oxford Univ Pr. $366 p$.

[NASS] National Agricultural Statistics Service. 2006. 2005 Almond Acreage Report. US Department of Agriculture. Sacramento, CA. 8 p. www.nass.usda. gov.

[OJEU] Official Journal of the European Union. 2007 Commission decision on aflatoxin contamination on
$\Delta$ A large-scale study in Kern County almond orchards found that navel orangeworm damage to nuts can be brought below $2 \%$ by reducing the average number of mummies per tree to 0.2 or fewer, and the average number of ground mummies to four or fewer per tree. By the time trees bloom in the spring, sanitation should be complete, since it is difficult to perform once new growth appears. products originating in the United States. Doc no. C(2007) 3613; Aug. 18, 2007. 3 p.

Schatzki TF, Ong MS. 2001. Dependence of aflatoxins in almonds on the type and amount of insect damage. J Ag Food Chem 49:4513-9.

Siegel JP, Kuenen LPS, Higbee BS, et al. 2008. Postharvest survival of navel orangeworm assessed in pistachios. Cal Ag 62:30-5.

[UC] University of California. 2006. Regional almond variety trials planted in 1993 progress report. UC Cooperative Extension and UC Davis. 26 p.

UC IPM Online. 2007. UC Pest Management Guidelines; Almond; Navel Orangeworm. www.ipm. ucdavis.edu/PMG/r3300311.html (accessed October 2007).

Wade WH. 1961. Biology of the navel orangeworm, Paramyelois transitella (Walker), on almonds and walnuts in northern California. Hilgardia 31:129-71.

Zalom FG, Barnett WW, Weakley CV. 1984. Efficacy of winter sanitation for managing the navel orangeworm, Paramyelois transitella (Walker), in California almond orchards. Prot Ecol 7:37-41. 